\title{
Hygro-Thermo-Mechanical Responses of Balsa Wood Core Sandwich Composite Beam Exposed to Fire
}

\author{
Luan TranVan ${ }^{1}$, Vincent Legrand ${ }^{2}$, Pascal Casari ${ }^{2}$, Revathy Sankaran ${ }^{3}{ }^{\circ}$, Pau Loke Show ${ }^{4, *}$, \\ Aydin Berenjian ${ }^{5, *}$ and Chyi-How Lay ${ }^{6}$ \\ 1 Faculty of Transportation Mechanical Engineering, the University of Da Nang-University of Science and \\ Technology, 54 Nguyen Luong Bang, Da Nang City 550 000, Vietnam; Tvluan@dut.udn.vn \\ 2 Institut de Recherche en Génie Civil et Mécanique (GeM) UMR CNRS 6183, Université de Nantes-Ecole \\ Centrale Nantes, Equipe Etat Mécanique et Microstructure des Matériaux (E3M), 58 rue Michel Ange, BP 420, \\ CEDEX 44606 Saint-Nazaire, France; vincent.legrand@univ-nantes.fr (V.L.); \\ pascal.casari@univ-nantes.fr (P.C.) \\ 3 Institute of Biological Sciences, Faculty of Science, University of Malaya, Kuala Lumpur 50603, Malaysia; \\ revathy@um.edu.my \\ 4 Department of Chemical Engineering, Faculty of Science and Engineering, University of Nottingham \\ Malaysia, Jalan Broga, Semenyih, Selangor Darul Ehsan 43500, Malaysia \\ 5 School of Engineering, Faculty of Science and Engineering, the University of Waikato, Hamilton 3240, \\ New Zealand \\ 6 Centre for General Education, Feng Chia University, Seatwen, Taichung 40724, Taiwan; chlay@fcu.edu.tw \\ * Correspondence: PauLoke.Show@nottingham.edu.my (P.L.S.); aydin.berenjian@waikato.ac.nz (A.B.)
}

Received: 15 December 2019; Accepted: 9 January 2020; Published: 13 January 2020

\begin{abstract}
In this study, the hygro-thermo-mechanical responses of balsa core sandwich structured composite was investigated by using experimental, analytical and numerical results. These investigations were performed on two types of specimen conditions: dry and moisture saturation sandwich composite specimens that are composed of E-glass/polyester skins bonded to a balsa core. The wet specimens were immersed in distilled water at $40{ }^{\circ} \mathrm{C}$ until saturated with water. The both dry and wet sandwich composite specimens were heated by fire. The mass loss kinetic and the mechanical properties were investigated by using a cone calorimeter following the ISO 5660 standard and three-point bending mechanical test device. Experimental data show that the permeability and fire resistance of the sandwich structure are controlled by two composite skins. Obtained results allow us to understand the Hygro-Thermo-Mechanical Responses of the sandwich structured composite under application conditions.
\end{abstract}

Keywords: sandwich composite fire; mechanical responses; moisture content; balsa core; mass loss kinetic; buckling failure

\section{Introduction}

The use of organic matrix composite materials has been continuously growing since the 1960s. As known to all, the material undergoes important physical and/or chemical modifications under extreme conditions, such as an appearance of metastable states or phase transitions [1,2]. Measurements in extreme conditions are facing scientific challenges to spot the properties of materials, and a technical challenge to apply new materials. Obviously, the increasing use of composites has reached a level that these materials compete with conventional materials such as steel and aluminium alloys in diverse areas, particularly aeronautics, aerospace and the shipbuilding industry due to their advantages in physical, chemical and mechanical properties [3-6]. 
Compared to other materials, organic matrix composites have low density, high specific stiffness and strength, good fatigue endurance and outstanding resistance to corrosion. However, there are several disadvantages compared to metals that include low impact tolerance, low fire performance and anisotropic properties [5-8]. Hence, the study on the effect of composite material properties under extreme conditions is needed to understand the behaviour and to optimize their properties. In the marine industry, the use of a sandwich structure consisting of a lightweight core made of polymer foam or balsa wood surrounded by thin stiff composite skins made of fiberglass and a major polymer as vinyl ester, epoxy or polyester, is common [5-8]. These combinations allowed a construction of an extraordinarily lightweight, durable and rigid structure. However, this type of material structure in the naval industry requires the special precaution of fire resistance. Composite sandwich materials are subject to strict regulation, and it is important to predict their thermomechanical properties as handling any applications [9-15]. The thermal degradation of materials as a composite sandwich have been widely described in detail $[1,2,8,16-21]$. There is limited study on the evaluation of the losses of the mechanical properties under the coupling effect of heat flux and moisture absorption. It is important to know the residual mechanical properties at room temperature of a burnt sandwich composite material in order to estimate the fire resistance of this structure after a fire exposure [9-13,15,21-25]. In this context, we were analysing the h hygro-thermo-mechanical responses of a sandwich structure composed of fiber-E-glass embedded in a polyester matrix, for the composition of the skins bonded to a balsa core. Previous studies focused on the thermal degradation of sandwich composite materials [15,23-25], and there are limited studies performed on the hygroscopically aged materials exploring the coupling hygro-thermo properties $[20,22,24]$. Officially, the water and temperature simultaneously could cause extreme degradation on the skins of this sandwich structure, thus the weak core would be exposed to application conditions. The resulting mechanical states of the core material can eventually induce the geometrical stability damage of such sandwich structure [13-15,23-25]. Balsa wood is widely used for cores of sandwich structures, especially in the shipbuilding industry due to its microstructure composing of long cells aligned in the axial direction which could provide the required axial strength and stiffness. However, only a few detailed studies were conducted on this subject [13-15,23-25]. Some research works focused specifically on the mechanical properties of balsa at high temperature and axial response failure under compression $[1,7,8,16]$.

In the present work, we focus on determining the mass loss kinetic and flexural behaviour under fire of the two types of dry and wet composite sandwich samples by using a cone calorimeter and a Zwick universal testing machine. The dry sandwich samples that were obtained from the shipbuilding industry were immersed in distilled water at $40^{\circ} \mathrm{C}$ until water saturation. Fire tests were processed with a heat flux of $50 \mathrm{~kW} / \mathrm{m}^{2}$ at different pyrolysis times. Additionally, a multi-layer analysis (skins and core) was conducted based on experimental results of the composite sandwich structure to estimate the hygro-thermo-mechanical properties of the global sandwich structure. This study enables the evaluation of the elastic modulus $\mathrm{E}$ and flexural load of the remaining sandwich structure material after enduring harsh working conditions such as exposure in water-fire.

\section{Experiment Set-Up}

\subsection{Sandwich Composite Materials}

The sandwich composite samples were made up of E-glass/polyester skins bonded to a balsa core by a direct infused process. These samples were cut from commercial plates that are used in the naval structure. Figure 1 indicated a studied E-glass/polyester/balsa sandwich specimen. The skins consist of E-glass fabric M450/QX868 made into a 2-plies layer surrounding the balsa core. The core was ordered to balsa wood pieces concocted in the form of about $50.0 \times 30.0 \times 16.0 \mathrm{~mm}^{3}$ blocks. The wood fiber direction $\left(\mathrm{D}_{3}\right)$ of the core is perpendicular to the composite skins. The average value of the balsa wood's density was $126 \pm 30 \mathrm{~kg} \mathrm{~m}^{-3}$. The coefficients $\mathrm{e}_{\mathrm{s}}=1.2(\mathrm{~mm}), 1=40.1(\mathrm{~mm}), \mathrm{l}^{*}=111.0$ 
$(\mathrm{mm})$ and e $=18.5(\mathrm{~mm})$, respectively, stand for the average skin thickness, average width, length and thickness of the sandwich specimens.

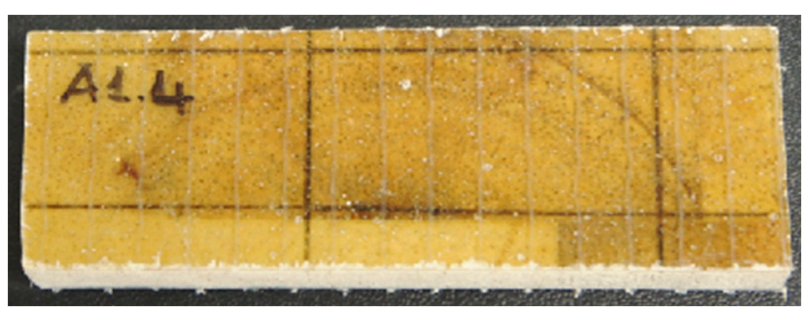

(a)

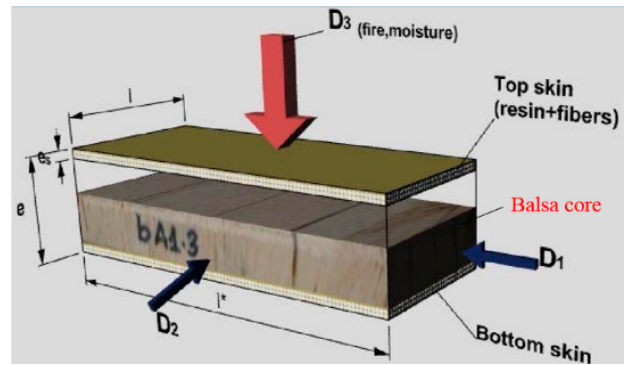

(b)

Figure 1. The studied E-glass/polyester/balsa sandwich composite beam specimen (a). Dimensions were illustrated the chosen directions of the moisture and heat flux. $D_{1}, D_{2}$ and $D_{3}$ are, respectively, the transverse directions and the thickness direction $(\mathbf{b})$.

\subsection{Experimental Measurements}

\subsubsection{Water Absorption Measurements}

The sandwich specimens for water uptake were dehydrated in an oven at $50{ }^{\circ} \mathrm{C}$ until the weight loss was stabilized, and they were then placed into a container at room temperature for $24 \mathrm{~h}$. The second step involves the complete immersion of specimens in distilled water at $40{ }^{\circ} \mathrm{C}$. In order to measure the quantity of the moisture absorption, the specimens were periodically removed out of the water bath one at a time, wiped off with an absorbent cloth, and immediately their mass was weighed. Sartorius, an MCBA 100 balance with precision ranging of (0-60) $\mathrm{g} \pm 0.1 \mathrm{mg},(61-110) \mathrm{g} \pm 0.2 \mathrm{mg}$ and (111-210) g $\pm 0.5 \mathrm{mg}$, was used. The moisture absorbed by the material at a specific time $\mathrm{M}(\mathrm{t})$ was experimentally determined by using the following equation:

$$
\mathrm{M}_{\mathrm{t}}=\frac{\mathrm{W}_{\mathrm{t}}-\mathrm{W}_{0}}{\mathrm{~W}_{0}} \times 100
$$

where, $W_{t}$ is the weight of the specimen at the immersion time $t$ and $W_{0}$ is the initial weight of the specimen. The weight measurements were taken initially at an interval of one quantification per day during the first 30 days, and later with a longer periodicity, since the mass fluctuations were not as large as during these days.

\subsubsection{Mass Loss Kinetic Measurements}

Fire-induced mass loss of the sandwich structured composite specimens were carried out using cone calorimetry (ISO 5660 standard). A radiative heat source was emitted from the cone constructed by winding an electrical resistance. The radiative source was kept at a uniform heat flux of $50 \mathrm{~kW}$ $\mathrm{m}^{-2}$. Gas flux was diluted with fresh air and drawn into a chimney. The ignition of the sandwich composite material was caused by a pilot spark. The temperature of the flame during a fire exposure of the material was $750{ }^{\circ} \mathrm{C}$. A surface of the test sample was positioned at a distance of $26 \mathrm{~mm}$ from the radiative source. Figure 2 shows the diagram of the position of the cone calorimetry heating setup. The direction of the heat flux was perpendicular to a surface of the sandwich sample test. During a fire resistance test time, the mass of the test sample was recorded as a function of the combustion time. For the purpose of quickly stopping the degradation of the combustion sample, we quickly removed a holder of the sample from the calorimeter cone and placed it into a chamber under nitrogen atmosphere. A residual mechanical property measurement was performed by using a Zwick universal 
testing machine. (Zwick Roell Group, Ulm, Germany). The mass loss kinetic measurement was conducted for the skin alone and the sandwich structured composite samples.

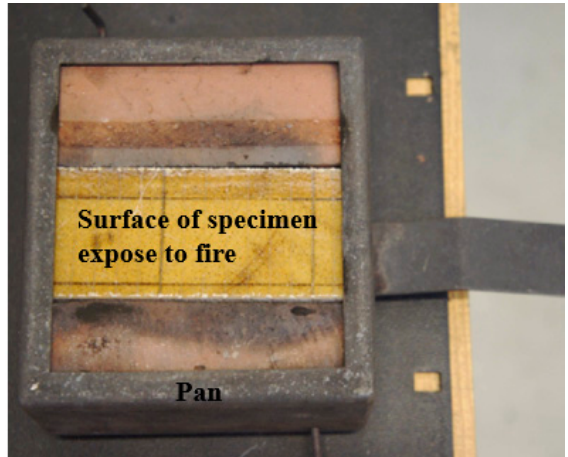

(a)

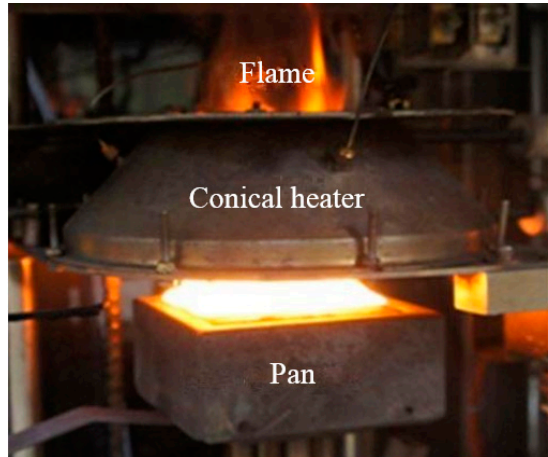

(b)

Figure 2. Diagram of the ATLAS cone calorimetry: holder of the test specimen (a), conical heater (b).

\subsubsection{Mechanical Property Measurement}

In order to measure a remaining mechanical property of the material after an exposure time to fire, a three-point bending flexural test was performed on the samples that underwent the thermal degradation processes. Both unaged and thermally-aged sample types were measured for the maximum flexural force reached before failure as a function of degradation time. The Zwick universal testing machine with $15 \mathrm{~mm}$ radius supports was used with a displacement speed of $10 \mathrm{~mm} \mathrm{~min}^{-1}$. During the test, both the flexural force and displacement of the test specimen were recorded. Figure 3 shows the supporting and the device for the three-point bending tests.

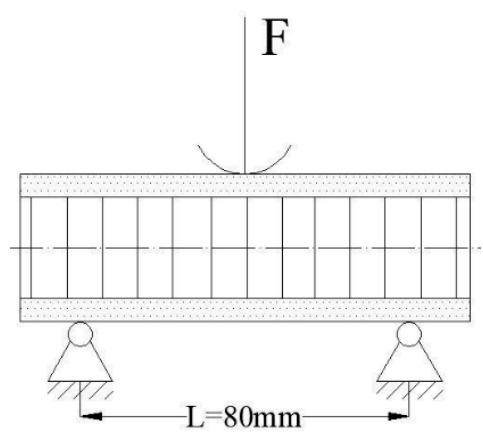

(a)

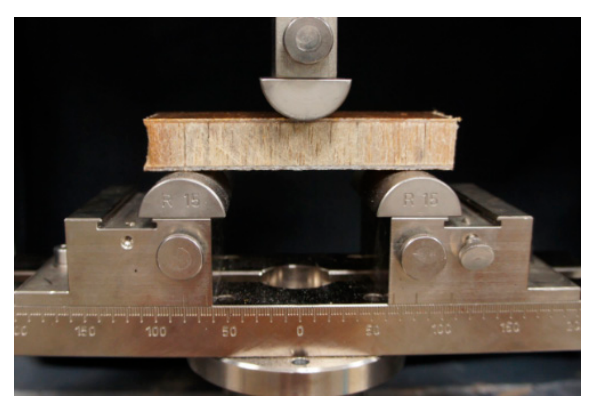

(b)

Figure 3. Sketch of the supporting (a) and the device (b) for the three-point bending tests of sandwich beams.

\section{Experimental Results}

\subsection{Moisture Diffusion}

If balsa wood immersed in water, the moisture will absorb in two ways: the first water floods in free volumes (cracks, hollow fibers) and the second moisture diffuses the dense material. Thus, in the single balsa wood, the moisture is quickly absorbed, and the moisture content obtained is high [6,7]. In the case of balsa as the core materialin sandwich composite structures, the skins acted as waterproof barriers, and infusion resin made full an important amount of hollow fibers for the moisture's viable passage. Figure 4 showed the moisture absorption characterization in both the composite sandwich structure and the bi-blade (balsa core + skin) specimens. The polyester/E-glass fibers skins played as a 
boundary which limits the water diffusion in the longitudinal direction of the wood fibers. Thus, the sandwich structure absorbed the relative moisture slowly.

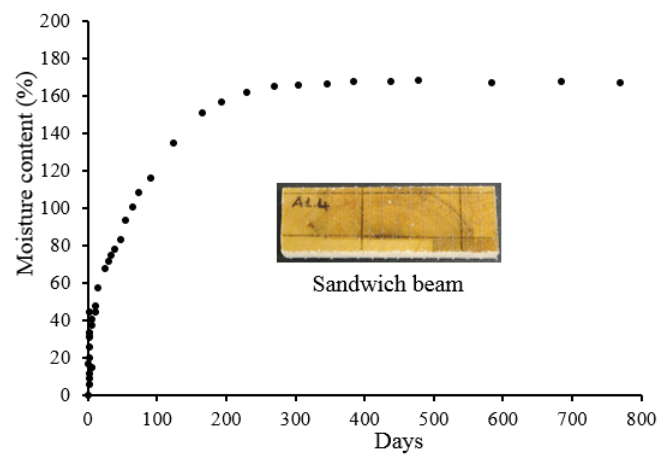

(a)

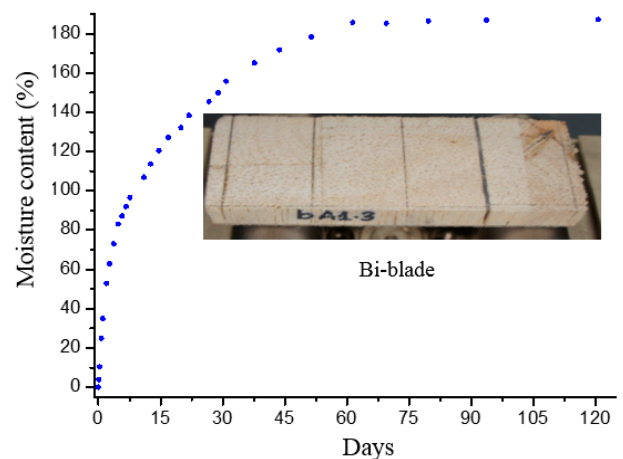

(b)

Figure 4. Diffusion kinetics of moisture at $40{ }^{\circ} \mathrm{C}$ in a sandwich beam (a) and a bi-blade (one skin and a core) (b).

The moisture content obtained in the sandwich material was lower than the bi-blade (balsa core + skin). This is due to the presence of one skin which limits moisture diffusion in one side of the sandwich structure. Figure $4 \mathrm{a}$ shows that the moisture diffusion was saturated in the sandwich structure after 400 days of immersion. For the bi-blade, the moisture saturation obtained after 75 days. This difference in the saturation time is due to the skins conducting a high restriction to the moisture penetration inside the material. Note that there is a large difference in the moisture content between both of the specimen types. The water absorption limitation corresponds to the value of the moisture content gain (Figure 4), which is approximately $180 \%$ for the bi-blade structure, and only $160 \%$ for the sandwich structure, even though the water diffusion takes place in three sides of the specimen. This measured value is consistent with values in the written works of the composite sandwich structure and single balsa $[6,8,19,26]$.

\subsection{Mass Loss Kinetic}

In order to understand the hygro-thermo-mechanical responses of the sandwich structured composite, it is necessary to know the mass loss kinetic property of this structure. Thus, the two specimen types were measured: single skin and the entire sandwich structured composite. The skin consists of polyester resin and E-glass fibers, and the core is made of balsa wood impregnated with resin. The skin is practically insensitive to water uptake, whereas the water content in the core is very high, reaching more than $400 \%[6,7]$. So, it is expected to know a fire response between the dry and the moisture saturation sandwich structured composite specimens.

In the first approximation for this paper, we consider that the fire response of the dry composite skin and the skin hygroscopically aged are similar because the skin absorbed a negligible amount of water. We therefore separated the skin from a dry sandwich composite sample (dimensions are indicated in Section 2.1), and measured its fire resistance property under $50 \mathrm{KW} \mathrm{m^{-2 }}$ heat flux and 750 ${ }^{\circ} \mathrm{C}$. The corresponding mass loss kinetic curve is shown in Figure 5. The entire combustion time was about $200 \mathrm{~s}$, and it induced a mass loss of $60 \%$ (initial mass $=10.99 \mathrm{~g}$ ). In the first $100 \mathrm{~s}$, the single skin lost about $50 \%$ of its weight. This result provides an estimation of the average mass loss rate of the composite skin of about $\mathrm{v}_{\mathrm{s}}=0.05 \mathrm{~g} \mathrm{~s}^{-1}$. At the start of the combustion, the skin burned and emitted a white smoke, and subsequently released a thick, black smoke. At the end of the combustion, only the fiberglass fabrics skin remained; the resin completely disappeared. 


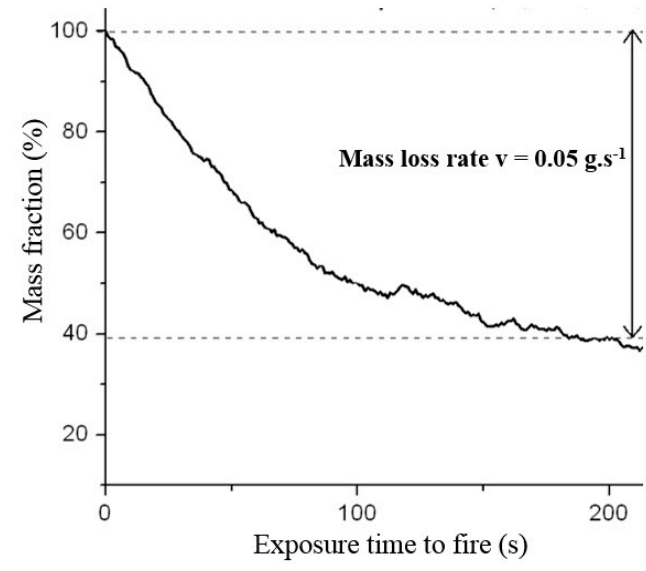

(a)

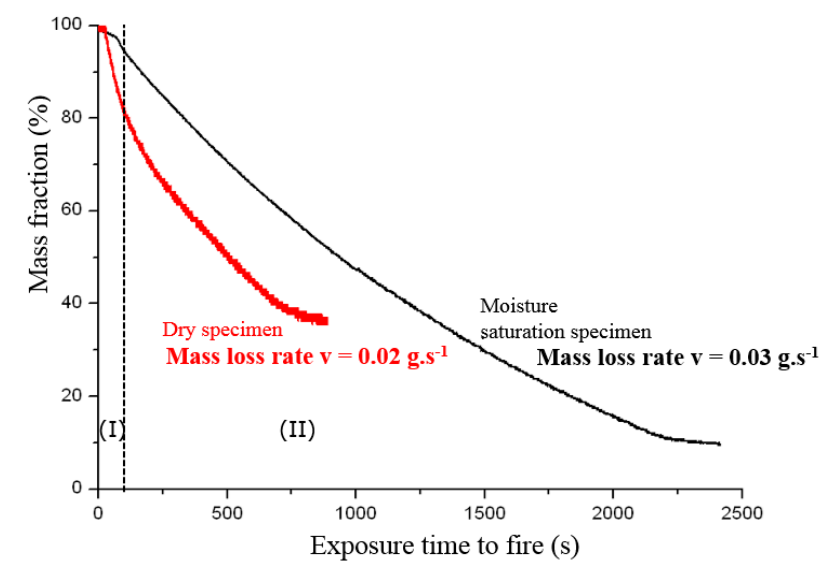

(b)

Figure 5. Mass loss curves as a function of fire exposure time for dry E-glass polyester single skin (a) and sandwich composite beam (b) from cone calorimetry measurements at $750{ }^{\circ} \mathrm{C}$.

For the dry sandwich specimen as shown on the Figure $5 \mathrm{~b}$, (initial mass $=38.06 \mathrm{~g}$ ), the material combustion curve was investigated in two successive portions: Portion I presents the pyrolyzed top skin, the exposure time to fire was $100 \mathrm{~s}$, induced loss mass $20 \%$ and the mass loss rate was equal to $\mathrm{v}_{\text {ts }}$ $=0.08 \mathrm{~g} \mathrm{~s}^{-1}$. Portion II respectively presents the char of the balsa core and the bottom skin, induced the loss mass about $45 \%$ during $775 \mathrm{~s}$ and the mass loss rate was about $0.02 \mathrm{~g} \mathrm{~s}^{-1}$. The incombustible mass was about $35 \%$ of the initial mass. Combustion products of the sandwich structured composite at the end of the degradation were left with glass fiber fabric and wood charcoal. The glass fiber fabric and wood charcoal did not degrade due to the pyrolysis temperature that was conducted $7500^{\circ} \mathrm{C}$, which is lower than the melting temperature of the glass fibers and the wood charcoal $[2,8,11]$. The obtained results of the sandwich structured composite was pyrolyzed by the cone calorimetry, and it was found that the kinetic mass loss characteristic of three elements (top skin-core-bottom skin) was discontinuous. There was a superposition of the combustion at interface between top skin-core and core-bottom skin. During the first $100 \mathrm{~s}$, the top skin was degraded and retracted by the heat flux, followed by the balsa core degradation. The top skin-core progressively induced delamination, an inflammation of the balsa core on the edges of the test specimen, and on resin between the balsa wood blocks. It made the balsa core lose its mass while the degradation in the top skin continues. The equivalent mass loss curve of the sandwich structure was obtained, which is the continuous curve in Figure $5 \mathrm{~b}$. The overview of the degradation processes on the cross section at different time intervals of the sandwich specimens during fire exposure is illustrated in Figure 6.

Finally, with the same measurements with above dry sandwich specimens, the determination of moisture saturation specimens (immersed in water at $40{ }^{\circ} \mathrm{C}$ ) were performed, (initial mass $=78.93$ g). Based on the observation, the fire behavior of the wet sandwich sample was similar to the dry sandwich sample. During the first $100 \mathrm{~s}$, the combustion of the top skin induced a mass loss about $5 \%$ and the mass loss rate was equal to $\mathrm{v}_{\mathrm{ts}}=0.04 \mathrm{~g} \mathrm{~s}^{-1}$. Then, the combustion of the equivalent bi-blade consisting of the balsa core and the bottom skin, induced a mass loss of $85 \%$ during $2150 \mathrm{~s}$, and the mass loss rate was equal to $0.03 \mathrm{~g} \mathrm{~s}^{-1}$. The remaining mass was about $10 \%$ of the initial mass of the test sample. Figure 5 presented that the evolution of the mass loss as a function of exposure time to fire of the moisture saturation sandwich sample. The degradation mechanism in the moisture saturation sandwich sample occurred slowly, but in the dry sandwich sample it occurred rapidly. This is because the water saturation sandwich sample contains a high water quantity which might significantly slow down the material pyrolysis. Thus, the complete deterioration due to fire of the water saturation sample was achieved in the $2250 \mathrm{~s}$. 


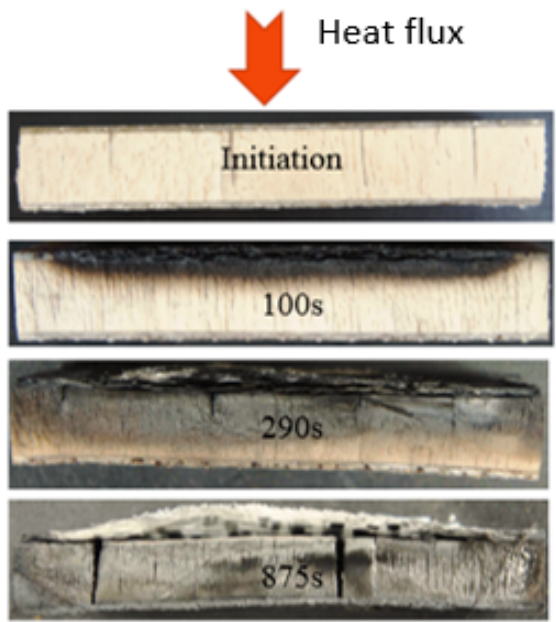

(a)

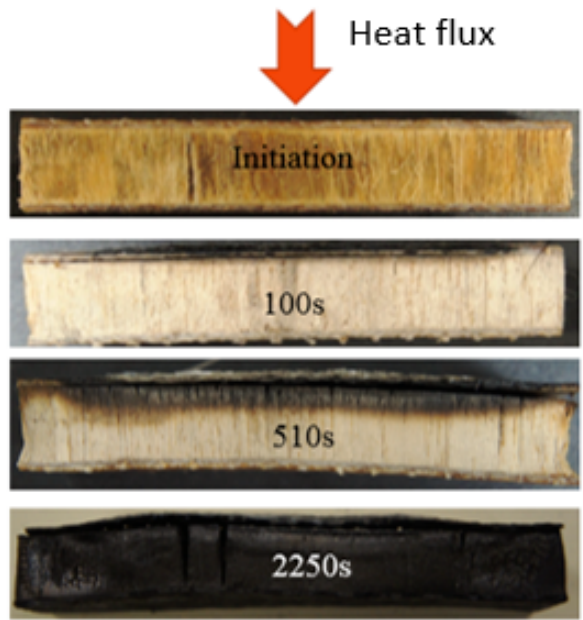

(b)

Figure 6. Cross-sectional view of the during fire exposure of the dry specimens (a) and the moisture saturation specimens (b).

\subsection{Post-Hygro-Thermo-Mechanical Properties}

Following mass loss measurements, the residual mechanical properties were determined to understand the hygro-thermo-mechanical response of these materials. Three-point bending measurements were performed on dry and water saturation samples at different times of the fire exposure. This analysis allows examining the residual mechanical strength of the sandwich structured composite after fire exposure.

Thus, the first step is to measure the ability of the sandwich structure to transmit a load up to the elastic limit. Figure 7 illustrated the evolution of the force as a function of displacement for dry and water saturation sandwich samples that did not undergo heat treatment. The mechanical behaviour consists of three periods: the first (period I) is similarly a behaviour of the porous materials. The displacement increases while the force is constant. This is supposed to be due to a change of the free volume of the top composite skins that were directly subjected to the action force. Thus, the residual deformation is maintained after discharge. A linear elastic behaviour of the sandwich structured composite material was observed. The force increases linearly with the displacement. Therefore, this linear portion of the curve was selected to make definite the Young's modulus. The final portion of the curve in period I corresponds to a nonlinear behaviour of the material until the abrupt rupture of the specimen. At the beginning of this phase, the force increases which corresponds to a small displacement. This clearly demonstrates that the flexural stiffness of the sandwich structure is improved by the shear stiffness of the balsa core. The end of this phase highlights a failure mode of the balsa core. The core is major enforced to shear, and failure takes place as the critical value (shear strength) of the core material is attained by the maximum shear stress. In the case of the moisture saturation specimen, after reaching critical load, the specimen did not break completely. The large amount of water contained in the core made it more elastic, so there was then a period of internal structure reorganization with constant force (period II). Finally, the force increases linearly with the increase of displacement (period III). The end of this period corresponds to a nonlinear behaviour of the moisture material until the rupture of the specimen. The critical load of the moisture specimen is lower than this one of the dry specimen, but the elastic deformation of the moisture specimen is larger by about 1.5 times. Figure $7 \mathrm{~b}$ shows the failure mode of dry and water saturation sandwich specimens. 


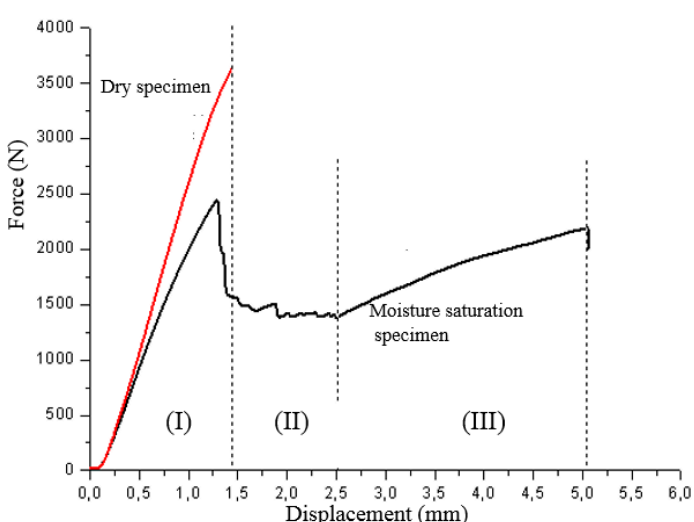

(a)

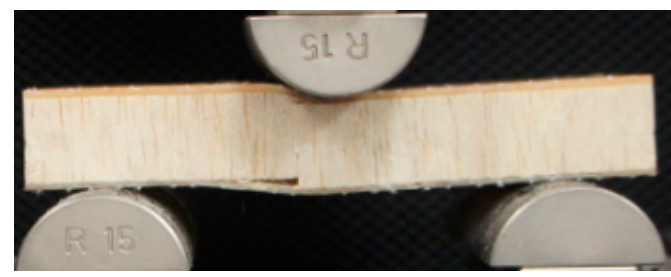

(b)

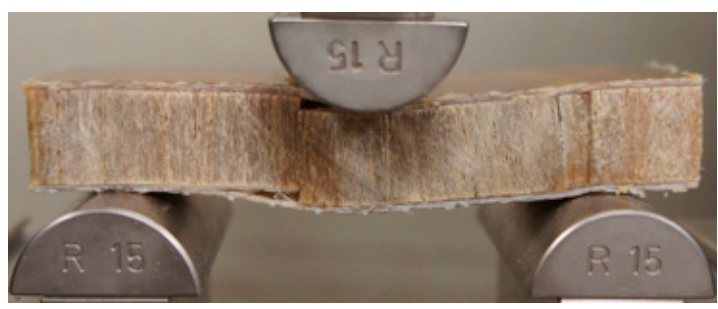

(c)

Figure 7. Three-point bending test: Force-displacement curve of the dry and water saturation sandwich specimens (a), failure mode of dry sandwich specimen (b) and water saturation sandwich specimen $(\mathbf{c})$.

The second step was to measure the hygro-thermo-mechanical properties of the sandwich composite beam. The failure mode of the sandwich beam is characterized by two parts. The first is the core's shear failure and the second failure is due to global buckling of the skins. The displacement obtained by the three-point bending test is therefore composed of two parts: the deflection due to global buckling and the displacement caused by shear deformation of the core. The total displacement is expressed as follows $[13,22,24]$ :

$$
\frac{\delta}{F L}=\frac{L^{2}}{48 D}+\frac{1}{4 S}
$$

where $\delta$ is the displacement $(\mathrm{mm})$ measured at mid-span under load $F(\mathrm{~N}) . L$ is the span length $(\mathrm{mm})$, $D=I E$ is the flexural stiffness of the sandwich beam $\left(\mathrm{N} \cdot \mathrm{mm}^{2}\right)$ within $E(\mathrm{MPa})$ is the Young's modulus I is the inertia moment, and $S=\mathrm{Gel}$ is the shear stiffness of the sandwich beam $(\mathrm{N})$ with $\mathrm{G}$ being the shear modulus (MPa). The coefficients $l$ and $e$ are, respectively, the width and the thickness of the sandwich specimen. Equation (2) is used to determine the values of the Young's modulus $E$ and the shear modulus $G$ of the specimen by measuring three-point bending for five sandwich beam specimens with the different values of $L$. The corresponding curve is represented in the Figure 8 as well as the equation of the line obtained by linear regression analysis on the experimental points. The calculated values of the Young's modulus is $E=7.8 \times 10^{3} \mathrm{MPa}$ and of the shear modulus, it is $G=85.9 \mathrm{MPa}$ for the dry balsa core sandwich beam specimen. Results are coincident with one found in the research in the particular case for pure balsa wood or E-glass-reinforced polyester resin $[2,3,6,7,12]$.

It is supposed that the parameter (1/(4S)) of the Equation (2) is corresponding to zero (Ignoring the contribution of core to the flexural stiffness). The Equation (2) is also rewritten to identify the Young's modulus $E$ as follows:

$$
E=\frac{L^{3}}{4 l e^{3}} \times \frac{F}{\delta}
$$

Identification of the elastic modulus $E$ is performed by using the analytical resolving method, given by the Equation (3) and the experimental results $F$ and $\delta$, obtained by three-point bending test.

Finally, the residual flexural mechanical responses were investigated on the dry and moisture saturation sandwich beam specimens. The normalized evolutions of the maximum force and the Young's modulus as a function of the time exposed to fire are shown in Figure 9. These plots show the thermo-mechanical responses as the maximum force $\left(F_{m}\right)$ and the flexural modulus $(E)$ decreases followed exponential law. This law had also been observed for other composite materials $[2-4,9,27]$. 
The dry and water saturation sandwich structured composite materials lost their mechanical properties during $100 \mathrm{~s}$ of exposure time to fire. This time characteristic corresponds to the thermal degradation of the top skin. When the top skin is degraded to weaken the sandwich structure, the maximum force and the flexural modulus decreases like the exponential law. The dependence of the thermo-mechanical properties on the moisture content is visible in Figure 9. These obtained experimental results indicate that the sandwich structured composite specimen and the thermo-mechanical responses significantly related to the degradation of the top skin, and they are not assured of the moisture content in the balsa core. The moisture concentration only strongly influences the duration of the fire exposure. The normalized force curve expresses a light disparity between dry and moisture materials and the normalized Young's modulus indicated the similar trend. Thus, it allows us to express that the relative elasticity of the sandwich material is independent of the internal water concentration, but it is significantly influenced by the duration of the fire exposure time. Figure 10 represents the cross-section of the sandwich structured composite beam after $100 \mathrm{~s}$ exposed to fire for the dry and the moisture saturation specimens to confirm well the weakened sandwich structure due to the degradation of its top skin.

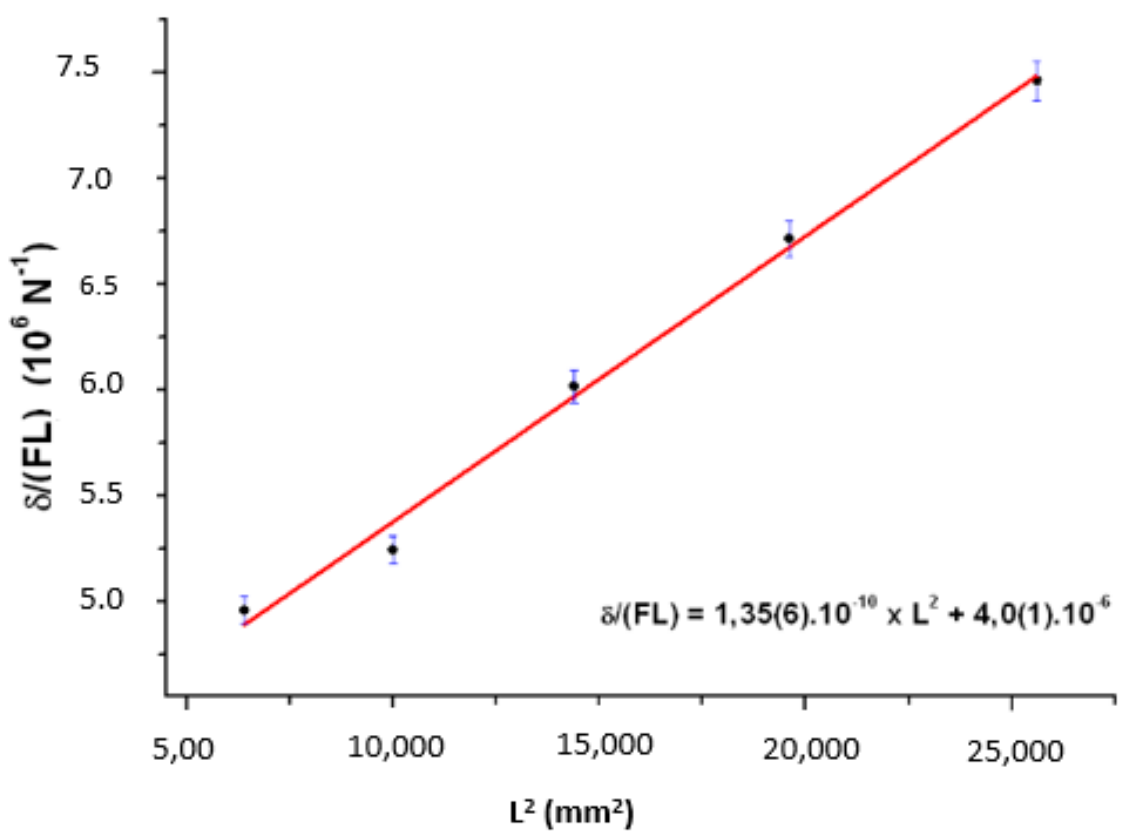

Figure 8. The curve of the $\delta /(F L)=L^{2}$ to determine the Young's modulus $(E)$ and the shear modulus $(G)$.

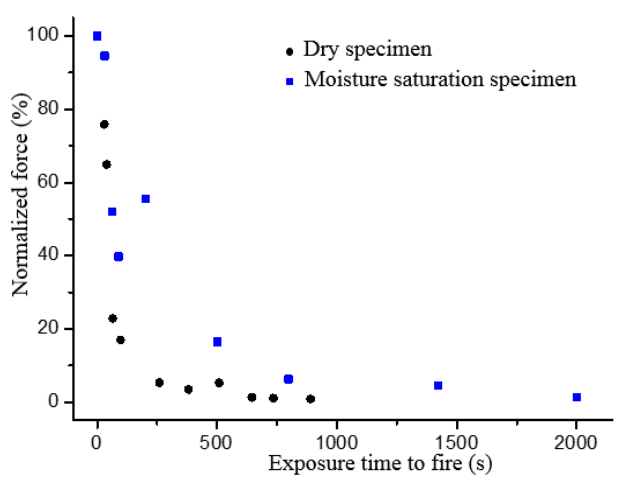

(a)

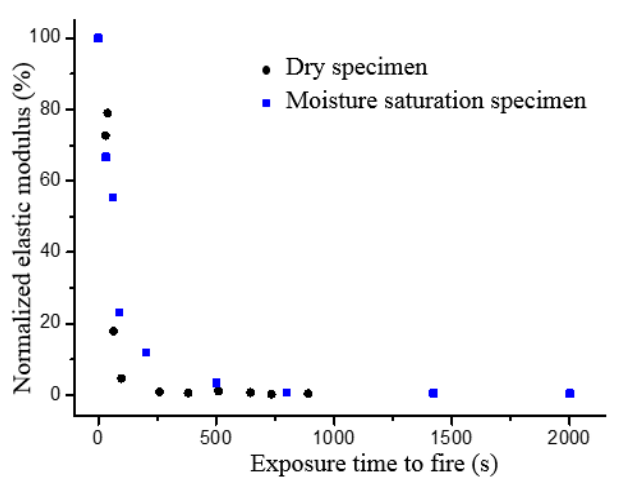

(b)

Figure 9. Post-residual flexural mechanical responses as a function of fire exposure time: normalized residual force (a) and normalized residual modulus (b). 

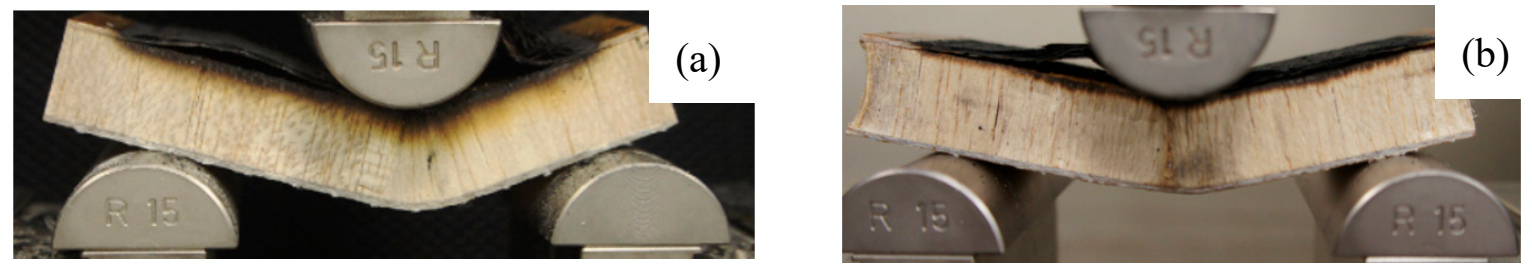

Figure 10. Cross-section of the sandwich structured composite beam after $100 \mathrm{~s}$ exposed to fire for the dry specimen (a) and the moisture saturation specimen (b).

\section{Conclusions}

The diffusive behaviour of the sandwich specimen and the bi-blade specimen (one skin and core) were investigated to understand the moisture impervious barrier significance of the skin. Thermal degradation rates under fire were identified for each skin and bi-blade sandwich specimens. The residual flexural mechanical responses as a function of the fire exposure time under a heat flux of 50 $\mathrm{kW} \mathrm{m}{ }^{-2}$ and $750{ }^{\circ} \mathrm{C}$ were analysed for the dry and moisture saturation sandwich specimens. The obtained results show that the sandwich structure undergoes a rapid thermo-mechanical degradation in the first $100 \mathrm{~s}$ of fire exposure, and this degradation is strongly influenced by the degradation of the top skin. Although the relative elasticity modulus of the sandwich structure composite material is independent of the moisture content, it is strongly influenced by the fire exposure time.

Author Contributions: Conceptualization, L.T.; Data curation, V.L.; Methodology, Software and Resources: P.C.; Original Draft Writing: L.T. and R.S.; Review \& Editing: R.S.; Supervision: P.L.S. and A.B.; Project Administration: P.L.S. and C.-H.L. All authors have read and agreed to the published version of the manuscript.

Funding: This research received no external funding.

Acknowledgments: Luan TranVan is indebted to the Ministry of Education and Training (MOET) for funding under grant number KYTH-74 (B2017.DNA.11). We would like to thank Didier Andeler and Philippe Frétaud (IUT Saint-Nazaire, France) for technical support.

Conflicts of Interest: The authors declare no conflict of interest in any choice of research project funding sponsors; design of the study; in the collection, analyses or interpretation of data; in the writing of the manuscript; or in the decision to publish the results.

\section{References}

1. Lua, J. Hybrid Progressive Damage Prediction Model for Loaded Marine Sandwich Composite Structures Subjected to a Fire. Fire Technol. 2011, 47, 851-885. [CrossRef]

2. Mouritz, A.; Mathys, Z.; Gardiner, C. Thermomechanical modelling the fire properties of fibre-polymer composites. Compos. Part B Eng. 2004, 35, 467-474. [CrossRef]

3. Ulven, C.A.; Vaidya, U.K. Post-fire low velocity impact response of marine grade sandwich composites. Compos. Part A Appl. Sci. Manuf. 2006, 37, 997-1004. [CrossRef]

4. Mouritz, A.P.; Feih, S.; Kandare, E.; Mathys, Z.; Gibson, A.G.; Des Jardin, P.E.; Case, S.W.; Lattimer, B.Y. Review of fire structural modelling of polymer composites. Compos. Part A Appl. Sci. Manuf. 2009, 40, 1800-1814. [CrossRef]

5. Joshi, N.; Muliana, A. Deformation in viscoelastic sandwich composites subject to moisture diffusion. Compos. Struct. 2010, 92, 254-264. [CrossRef]

6. Legrand, V.; TranVan, L.; Jacquemin, F.; Casari, P. Moisture-uptake induced internal stresses in balsa core sandwich composite plate: Modeling and experimental. Compos. Struct. 2014, 119, 355-364. [CrossRef]

7. Tranvan, L.; Legrand, V.; Jacquemin, F. Thermal decomposition kinetics of balsa wood: Kinetics and degradation mechanisms comparison between dry and moisturized materials. Polym. Degrad. Stab. 2014, 110, 208-215. [CrossRef]

8. Mouritz, A.P. Fire resistance of aircraft composite laminates. J. Mater. Sci. Lett. 2003, 22, 1507-1509. [CrossRef]

9. Sereir, Z.; Adda-bedia, E.A.; Boualem, N. The evolution of transverse stresses in hybrid composites under hygrothermal loading. Mater. Des. 2011, 32, 3120-3126. [CrossRef] 
10. Sinmazçelik, T.; Avcu, E.; Bora, M.Ö.; Çoban, O. A review: Fibre metal laminates, background, bonding types and applied test methods. Mater. Des. 2011, 32, 3671-3685. [CrossRef]

11. Frostig, Y. Hygothermal (environmental) effects in high-order bending of sandwich beams with a flexible core and a discontinuous skin. Compos. Struct. 1997, 37, 205-221. [CrossRef]

12. Le Duigou, A.; Deux, J.M.; Davies, P.; Baley, C. PLLA/flax mat/balsa bio-sandwich manufacture and mechanical properties. Appl. Compos. Mater. 2011, 18, 421-438. [CrossRef]

13. Steeves, C.A.; Fleck, N.A. Collapse mechanisms of sandwich beams with composite faces and a foam core, loaded in three-point bending. Part II: Experimental investigation and numerical modelling. Int. J. Mech. Sci. 2004, 46, 585-608. [CrossRef]

14. Tagarielli, V.L.; Fleck, N.A.; Deshpande, V.S. Collapse of clamped and simply supported composite sandwich beams in three-point bending. Compos. Part B Eng. 2004, 35, 523-534. [CrossRef]

15. Manalo, A.C.; Aravinthan, T.; Karunasena, W. Flexural behaviour of glue-laminated fibre composite sandwich beams. Compos. Struct. 2010, 92, 2703-2711. [CrossRef]

16. Zhu, F.; Li, K. Numerical Modeling of Heat and Moisture Through Wet Cotton Fabric Using the Method of Chemical Thermodynamic Law Under Simulated Fire. Fire Technol. 2011, 47, 801-819. [CrossRef]

17. Voss, M.; Wannicke, N.; Deutsch, B.; Bronk, D.; Sipler, R.; Purvaja, R.; Ramesh, R.; Rixen, T. Internal Cycling of Nitrogen and Nitrogen Transformations. In Treatise on Estuarine and Coastal Science; Academic Press: Cambridge, MA, USA, 2012; ISBN 9780080878850.

18. Gigliotti, M.; Jacquemin, F.; Vautrin, A. Assessment of approximate models to evaluate transient and cyclical hygrothermoelastic stress in composite plates. Int. J. Solids Struct. 2007, 44, 733-759. [CrossRef]

19. Choi, H.S.; Jang, Y.H. Bondline strength evaluation of cocure/precured honeycomb sandwich structures under aircraft hygro and repair environments. Compos. Part A Appl. Sci. Manuf. 2010, 41, 1138-1147. [CrossRef]

20. Abot, J.L.; Yasmin, A.; Daniel, I.M. Hygroscopic behavior of woven fabric carbon-Epoxy composites. J. Reinf. Plast. Compos. 2005, 24, 195-207. [CrossRef]

21. Fiore, V.; Di Bella, G.; Valenza, A. Glass-basalt/epoxy hybrid composites for marine applications. Mater. Des. 2011, 32, 2091-2099. [CrossRef]

22. Steeves, C.A.; Fleck, N.A. Material selection in sandwich beam construction. Scr. Mater. 2004, 50, 1335-1339. [CrossRef]

23. Bažant, Z.P.; Beghini, A. Sandwich buckling formulas and applicability of standard computational algorithm for finite strain. Compos. Part B Eng. 2004, 35, 573-581. [CrossRef]

24. Reyes, G.; Rangaraj, S. Fracture properties of high performance carbon foam sandwich structures. Compos. Part A Appl. Sci. Manuf. 2011, 42, 1-7. [CrossRef]

25. Chen, C.; Harte, A.M.; Fleck, N.A. Plastic collapse of sandwich beams with a metallic foam core. Int. J. Mech. Sci. 2001, 43, 1483-1506. [CrossRef]

26. Chen, H.; Miao, M.; Ding, X. Influence of moisture absorption on the interfacial strength of bamboo/vinyl ester composites. Compos. Part A Appl. Sci. Manuf. 2009, 40, 2013-2019. [CrossRef]

27. Le Lay, F.; Gutierrez, J. Improvement of the fire behaviour of composite materials for naval application. Polym. Degrad. Stab. 1999, 64, 397-401. [CrossRef]

(C) 2020 by the authors. Licensee MDPI, Basel, Switzerland. This article is an open access article distributed under the terms and conditions of the Creative Commons Attribution (CC BY) license (http://creativecommons.org/licenses/by/4.0/). 